\title{
Current perception thresholds: a new, quick, and reproducible method for the assessment of peripheral neuropathy in diabetes mellitus
}

\author{
E. A. Masson, A. Veves, D. Fernando and A. J.M.Boulton \\ Department of Medicine, Manchester Royal Infirmary, Manchester, UK
}

\begin{abstract}
Summary. The Neurometer is a variable constant current sine wave stimulator, and has recently been proposed as a simple non-invasive and quantitative measure of peripheral nerve function. The device is portable and battery operated; assessment of upper and lower extremities takes only a few min, in contrast to conventional assessment techniques. In order to assess its potential in the quantification of diabetic neuropathy, detection thresholds for constant current electric sine wave stimulation were measured at three different frequencies in different sites in 31 healthy control subjects and 90 diabetic patients with and without neuropathy. The device provides good discrimination between neuropathic and non-neuro-
\end{abstract}

pathic groups $(p<0.001)$ and is quick and easy to use. Comparisons with results of conventional tests of nerve function show that high frequency detection thresholds correlate best with tests of large fibre function $(r=0.42-0.69, p<0.001)$, and low frequency detection thresholds correlate with tests of small fibre function $(r=0.34-0.46, p<0.005)$. It is concluded that the device may be a simple and comprehensive way of assessing peripheral nerve function.

Key words: Neurometer, diabetic neuropathy, vibration perception, nerve conduction.
Established methods for the quantification of peripheral nerve dysfunction include the measurement of individual nerve conduction velocities, and objective measures of sensory perception for either mechanical or thermal stimuli. Measurement of conduction velocities requires considerable skill and experience on the part of the operator, expensive equipment, and can be uncomfortable for the patient. It is quite reproducible but quantifies only the function of large myelinated fibres. Nerve conduction measurements have for some time been regarded by many as the key investigation of nerve integrity [1]. Psychophysical measurements of 'objective' thresholds for sensory perception have been measured in a variety of ways, from simple deformable monofilaments [2] through various types of devices for producing graded vibratory and thermal stimuli [3-7], to highly sophisticated computer-aided laboratory systems [8]. Many of the techniques are difficult to standardise [9], and particularly for thermal testing the reported normal discrimination thresholds vary a great deal depending on the machine used $[3,6]$. Maintaining the full attention of the patient is necessary for accurate reproducibility, which can be difficult if the testing procedures are timeconsuming, as most of the currently available thermal testers are. Despite these problems, most authorities agree that the measurement of sensory thresholds for small and large fibre functions is essential for full characterisation of diabetic neuropathy $[10,11]$.

We have evaluated a new device which has not previously been tested in Great Britain, for the assessment of diabetic peripheral neuropathy, and compared it with conventional methods for quantification of neurological dysfunction. The device uses a novel stimulus, an electric sine wave of up to $10 \mathrm{~mA}$ produced by a portable battery powered constant current generator. The current output of the generator is maintained continuously by a feedback circuit during the procedure, so that alterations in skin resistance are automatically compensated for. The minimum amplitude of signal required to produce a sensation is determined at three different frequencies. The stimulating electrodes are small and can be attached to any body site, simply by taping them to the skin.

\section{Patients and methods}

The Neurometer (Minimed Technologies, Sylmar, Calif, USA) was initially performance tested by the medical physics laboratory. Thirtyone control subjects (Group 1) and 90 patients with Type 1 (insulin- 
Table 1. Clinical details of subjects studied

\begin{tabular}{|c|c|c|c|c|c|c|c|}
\hline \multirow[t]{2}{*}{ Subjects } & \multirow{2}{*}{$\begin{array}{l}\text { Sex } \\
\mathrm{M} / \mathrm{F} \\
(n)\end{array}$} & \multicolumn{2}{|c|}{ Age (years) } & \multicolumn{2}{|c|}{$\begin{array}{l}\text { Duration of } \\
\text { diabetes (years) }\end{array}$} & \multirow{2}{*}{$\begin{array}{l}\text { Type } 1 \\
\text { (insulin- } \\
\text { dependent) } \\
\text { diabetes }(n)\end{array}$} & \multirow{2}{*}{$\begin{array}{l}\text { Type } 2 \\
\text { (non-insulin } \\
\text { dependent) } \\
\text { diabetes }(n)\end{array}$} \\
\hline & & Mean & Range & Mean & Range & & \\
\hline $\begin{array}{l}\text { Diabetic } \\
\text { (Group 2, } \\
n=35 \text { ) }\end{array}$ & $14 / 21$ & 47 & $18-79$ & 14 & $1-40$ & 19 & 16 \\
\hline $\begin{array}{l}\text { Diabetic } \\
\text { Neuropathy } \\
\text { (Group 3, } \\
n=34 \text { ) }\end{array}$ & $23 / 11$ & 52 & $26-72$ & 17 & $1-42$ & 13 & 21 \\
\hline $\begin{array}{l}\text { Diabetic } \\
\text { Neuropathic } \\
\text { Ulcer } \\
\text { (Group 4, } \\
n=21 \text { ) }\end{array}$ & $16 / 5$ & 53 & $37-64$ & 18 & $1-54$ & 12 & 9 \\
\hline
\end{tabular}

dependent) and Type 2 (non-insulin-dependent) diabetes mellitus then participated in the study, which was approved by the Central Manchester Hospitals Ethical Committee. The diabetic patients were divided into 3 clinical groups: those with no evidence of peripheral neuropathy (Group 2), patients with symptomatic neuropathy [12] (Group 3), and patients with a history of neuropathic foot ulceration (Group 4). Details of the groups are given in Table 1. Patients rested in a warm environment and current perception thresholds (CPT) were determined for $5 \mathrm{~Hz}, 250 \mathrm{~Hz}$, and $2 \mathrm{kHz}$ at two test sites: the index finger and the great toe. The stimulus was initially increased until a sensation was reported and then short stimuli $(2-5 \mathrm{~s})$ were applied at progressively lower amplitudes until a minimal threshold for consistent detection was determined. The device has a "dummy" switch to allow the the on/off status of the machine to be concealed from the patient, and a forced choice paradigm was used to confirm the minimum threshold for perception [8].

A cohort of 68 patients also had conventional assessment of peripheral nerve function. A biothesiometer (Bio-medical instrument $\mathrm{Co}$, Ohio, USA) was used for the measurement of vibration perception threshold at the tip of the great toe, and the distal interphalangeal joint of the index finger. Warm thermal discrimination thresholds were measured using the thermoaesthaesiometer [4] (Free University Hospital, Amsterdam, The Netherlands). Peroneal nerve motor conduction velocity was measured using surface electrodes and a Medelec electrophysiological system (Medelec MS92A Medelec Ltd, Old Woking, Surrey, UK).

\section{Statistical analysis}

Statistical analysis was carried out with non-parametric techniques (Mann-Whitney U-test, Spearman rank correlation coefficient) using the 'Amstat' statistical package for Amstrad computers (SC Coleman Ltd, Ashby-de-la-Zouch, UK).

\section{Results}

In laboratory conditions the device performed well to its specification, producing a pure sine wave of up to $10 \mathrm{~mA}$ (20 mA peak to peak) across an impedance of up to 6 kilo-ohms (maximum voltage $110 \mathrm{~V}$ ). The digital calibration of the machine proved to be very accurate.
In practice the Neurometer was easy to use, and did not induce discomfort. Assessment of two sites took about $10-15 \mathrm{~min}$ on average. Repeated measurements in a number of normal individuals revealed that the coefficient of variation of CPT measures was frequency dependent, with the smallest coefficient of variation seen with $2 \mathrm{kHz}$ stimuli (8-11\%) and the largest with low frequency stimuli (16-20\%), although the absolute variability was similar.

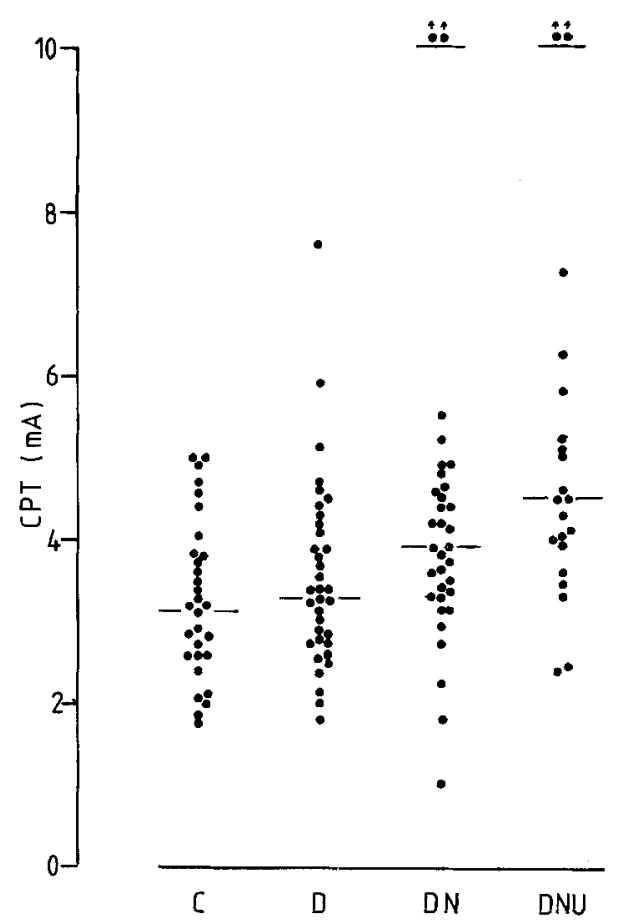

Fig. 1. Current perception threshold (CPT) distributions ( - median) for the 4 groups in the hand at $2 \mathrm{kHz}$. C - control; D - non-neuropathic diabetic; DN - diabetic neuropathy, no foot ulcer; DNU diabetic with history of neuropathic foot ulceration. C vs $D N$, $p<0.05 ; \mathrm{C}$ vs DNU, $p<0.001 ; \mathrm{D}$ vs DNU, $p<0.01$ 


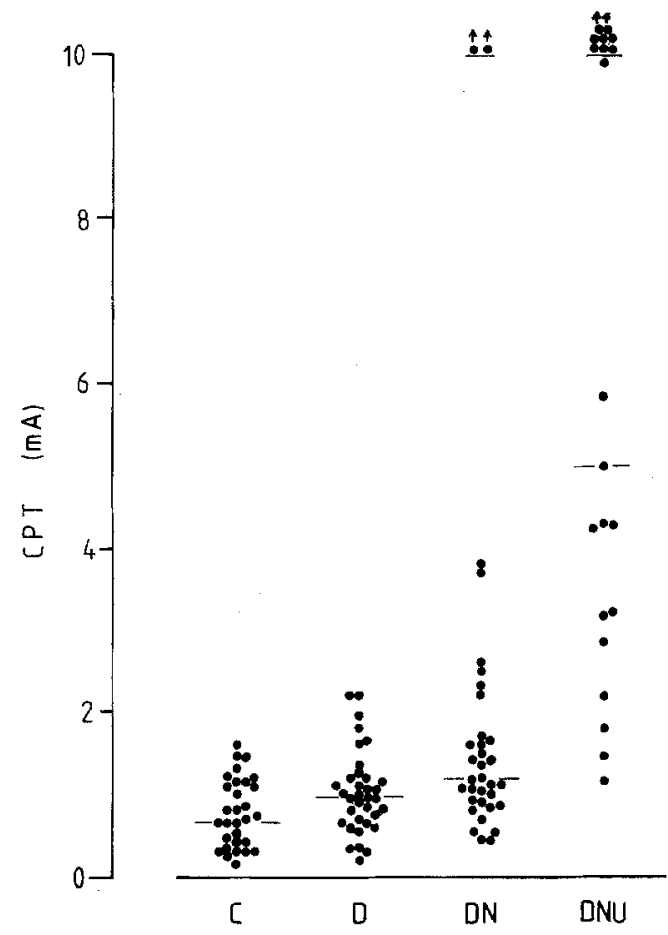

Fig. 2. Current perception threshold (CPT) distribution (- - median) for the 4 groups in the foot at $5 \mathrm{~Hz}$. $\mathrm{C}$ - control; D - non-neuropathic diabetic; DN - diabetic neuropathy, no foot ulcer; DNU - diabetic with history of neuropathic foot ulceration. $\mathrm{C}$ vs $\mathrm{DN}, p<0.001$; C vs $\mathrm{DNU}, p<0.001 ; \mathrm{D}$ vs $\mathrm{DN}, p<0.05 ; \mathrm{D}$ vs $\mathrm{DNU}, p<0.001$

The sensations evoked by the different stimulus frequencies were subjectively different. The descriptions of the sensations were similar in all groups, at least in the upper limb. With $5 \mathrm{~Hz}$ stimuli the sensations were typically described as 'burning' or 'stinging', and became unpleasant at stimulus intensities around twice the threshold for detection. In contrast $2 \mathrm{kHz}$ stimuli produced sensations of a more mechanical quality, described by words such as 'buzzing' or 'tingling'. Most subjects did not find that these sensations became unpleasant at increased stimulus amplitudes.

The results provided good discrimination between the neuropathic and non-neuropathic groups at all frequencies in the foot, and to some extent in the hand. Figure 1 shows the CPT measurements obtained at $2 \mathrm{kHz}$ in the finger for the 4 groups. The neuropathy (Group 3) patients' results were significantly different from control (Group 1, $p<0.05$ ), and those from the neuropathic ulcer (Group 4) patients were greater than control $(p<0.001)$, and the non-neuropathic diabetic patients (Group 2, $p<0.01$ ).

Figures 2-4 show the distributions of CPT measurements in the foot. Significant differences between neuropathic (Group 3 and 4), and non-neuropathic (Group 1 and 2) responses existed at all frequencies $(p<0.05-0.001)$.

Significant correlations were found between $2 \mathrm{kHz}$ CPT and measurements of large fibre function (vibra-

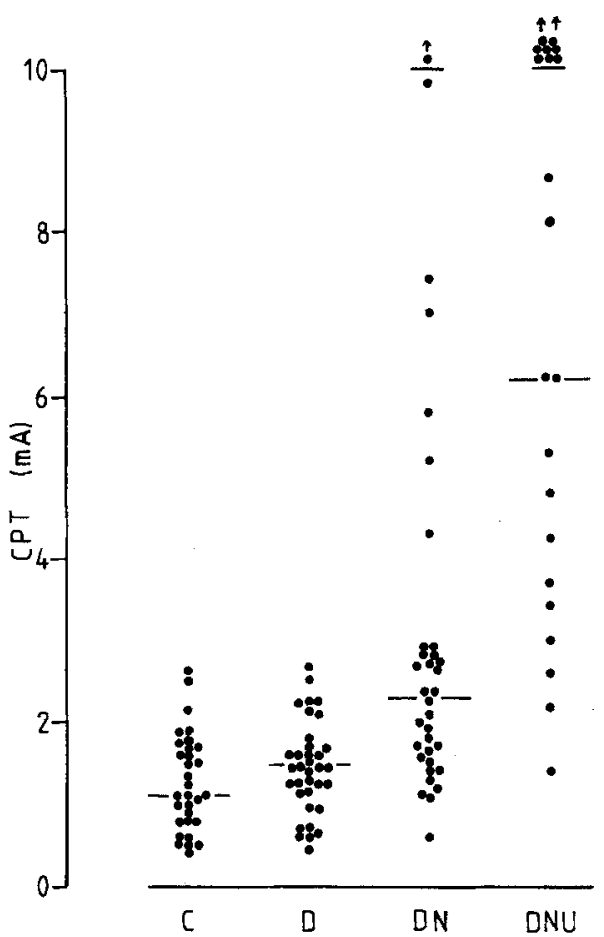

Fig. 3. Current perception threshold (CPT) distributions (- - median) for the 4 groups in the foot at $250 \mathrm{~Hz}$. C - control; D - non-neuropathic diabetic; DN - diabetic neuropathy, no foot ulcer; DNU diabetic with history of neuropathic foot ulceration. C vs DN, $p<0.001$; C vs DNU, $p<0.001$; D vs $\mathrm{DN}, p<0.001$; D vs DNU, $p<0.001$

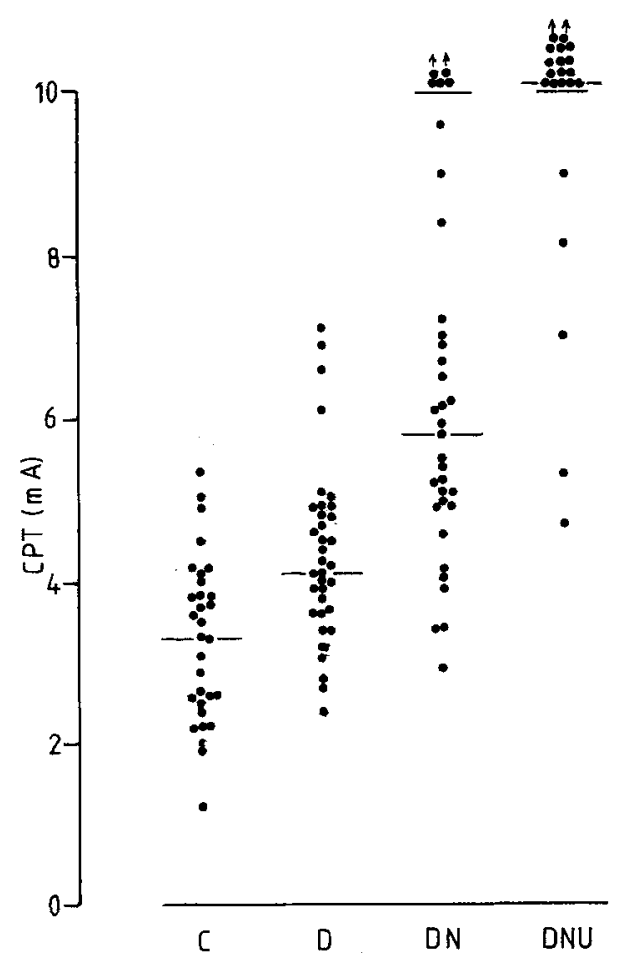

Fig.4. Current perception threshold (CPT) distributions (- - median) for the 4 groups in the foot at $2 \mathrm{kHz}$. C - control; D - non-neuropathic diabetic; DN - diabetic neuropathy, no foot ulcer; $\mathrm{DNU}$ - diabetic with history of neuropathic foot ulceration. C vs DN, $p<0.001$; C vs DNU, $p<0.001$; D vs DN, $p<0,001$; D vs DNU, $p<0.001$ 
Table 2. Significant correlations of current perception thresholds (CPT) and conventional tests

\begin{tabular}{lllll}
\hline \multicolumn{4}{l}{ Current perception threshold } \\
\cline { 2 - 5 } & $\begin{array}{l}5 / 250 \mathrm{~Hz} \\
\text { (hand) }\end{array}$ & $\begin{array}{l}5 \mathrm{~Hz} \\
\text { (foot) }\end{array}$ & $\begin{array}{l}2 \mathrm{kHz} \\
\text { (hand) }\end{array}$ & $\begin{array}{l}2 \mathrm{kHz} \\
\text { (foot) }\end{array}$ \\
\hline $\begin{array}{l}\log _{10} \text { Thermal } \\
\text { threshold }\end{array}$ & $0.37 / 0.46^{\mathrm{a}}$ & $0.34^{\mathrm{b}}$ & & \\
$\begin{array}{l}\text { Vibration } \\
\text { perception } \\
\text { threshold }\end{array}$ & & & \\
$\begin{array}{l}\text { Peroneal motor } \\
\text { conduction velocity }\end{array}$ & & $0.42^{\mathrm{a}}$ & $0.69^{\mathrm{a}}$ \\
\hline
\end{tabular}

Spearman correlation coefficients between CPT measures at different frequencies and conventional tests of sensory perception and conduction velocity

${ }^{\mathrm{a}} p<0.005 ;{ }^{\mathrm{b}} p<0.001$

tion perception and conduction velocity); small fibre function (thermal discrimination) correlated significantly with lower frequency CPT (Table 2).

\section{Discussion}

The Neurometer proved to be a simple and potentially a useful way of quantifying nerve dysfunction, and its use has certain advantages over conventional techniques. It is easily portable, and does not require great skill or experience to operate. It provides useful discrimination between neuropathic and non-neuropathic clinical groups, and may offer an indication for risk of foot ulceration in diabetic patients. Intrasubject variability of the measurement of CPT was similar in our experience to that described by other workers [13], and compares favourably with other sensory perception tests.

Conventional electrophysiology has been used for many years to assess neurological abnormality in diabetic patients, but has some associated problems. Some abnormality can be detected in the majority of patients [14], and the conduction velocity measured mostly reflects the integrity of large myelinated fibres, which constitute a numerical minority of nerve fibres. Although not relying on patient response and attention, a number of potential errors can occur. Nerve conduction velocity is temperature dependent, but temperature of the skin does not necessarily reflect temperature of the nerve. Although the latency of the electrical response can be determined with great accuracy, the distance between stimulus sites is measured at the skin surface and is therefore imprecise. However, if due attention is paid to these problems, much useful information can be obtained [1].

The commonest device used to assess vibration perception is the biothesiometer, which has no direct control of applied pressure, and is thus subject to operator and technique variability, as well as variation of percep- tion between sites [9]. This problem is controlled for by the Vibrameter (Somedic, Stockholm, Sweden) and the computer assisted sensory examination [8]. The latter also removes observer error, but is time consuming and impractical for screening purposes.

The most frequently applied test of small fibre function is to determine thermal discrimination thresholds, and there is probably a greater profusion of equipment and techniques for this than for any other sensory modality [3-6]. Although there is some consensus that a forced choice method is the best approach, this is not universal, and large differences are reported between normal ranges by different workers, depending on the methodology employed.

The Neurometer does rely on patient response, but there is no problem with the standardisation of electrode placement, or applied pressure. Forced choice determination of perception threshold can be carried out, and there is a warning light if the impedance across the electrodes exceeds the capacity of the machine to deliver a pure sine wave stimulus. The ability of the machine to maintain the current despite alterations in skin resistance may be the reason for the reproducibility of CPT measurements. If constant voltage stimuli are applied the current delivered is entirely dependent on skin resistance. We have found that the low variability of high frequency CPT approaches that of nerve conduction velocity measurement.

It has been suggested [13] that because the amplitude for perception is very different at the different test frequencies that the device is testing three different nerve fibre populations; but consideration of stimulus amplitude/duration relationships for action potential propagation [15] would lead one to expect this difference. However, different nerve fibre types show variable degrees of accommodation to slow depolarisation, the greatest accommodation occurring in large myelinated fibres, and the least in small fibres [16]. The relatively long rise time of a low frequency sine wave $(50 \mathrm{~ms}) \mathrm{might}$ allow large myelinated fibres to accommodate, and so fail to produce an action potential at low stimulus amplitudes. Furthermore, it has been demonstrated with the technique of microneurography that $\mathrm{C}$ fibres in human skin can be stimulated electrically at low frequencies, but that repetitive stimulation produces an increase in latency, and conduction blocking to a greater degree than that seen in larger fibres [17]. That the device is capable of giving information about the functional integrity of different fibre types is suggested by the correlations with thermal and vibration testing. The subjective sensations evoked also suggest a somewhat different pattern of fibre activation at different frequencies. It is by no means certain that transcutaneous stimulation with the Neurometer stimulates nerve fibres directly however, and it may be that the differential responses of cutaneous mechanoreceptors to different frequencies of mechanical stimulation $[18,19]$ is the mechanism by which different sensations are evoked. 
It should be remembered that all techniques for evaluating sensory function are not measuring peripheral nerve function specifically, and intepretation of results in this way assumes the integrity of central sensory pathways. This limits their use in screening for peripheral neuropathy, but the Neurometer may enable a comprehensive assessment to be made simply and rapidly, without the need for a complex laboratory. However, claims that the Neurometer can detect and quantify hyperaesthesia and diagnose neuropathy earlier than other techniques are more difficult to justify, and should be treated with caution.

In conclusion therefore, the Neurometer performed well in clinical practice, and appears to provide quantitative information about the integrity of both small and large fibres in peripheral nerve. Whilst it is unlikely to replace conventional techniques, its small size and portability make it useful for rapid assessment in the clinical situation.

Acknowledgements. EAM and AJMB are supported by the Wellcome Trust. We thank Minimed Technologies and Neurotron Inc for the loan of a Neurometer, the department of Medical Physics for testing the machine, and Professor S. Tomlinson for his help and support.

\section{References}

1. Brown MJ, Asbury AK (1984) Diabetic neuropathy. Ann Neurol 15: $2-12$

2. Birke JA, Sims DS (1986) Plantar sensory threshold in the ulcerative foot. Lepr Rev 57: 261-267

3. Jamal GA, Hansen S, Weir AI, Ballantyne JP (1985) An improved automated method for the measurement of thermal thresholds. 1. normal subjects. J Neurol Neurosurg Psychiatry 48: 354-360

4. Bertlesmann FW, Heimans JJ, Weber EJM, Van der Veen EA, Schouten JA (1985) Thermal discrimination thresholds in normal subjects and in patients with diabetic neuropathy. $J$ Neurol Neurosurg Psychiatry 48: 686-690

5. Fowler CJ, Carroll MB, Burns D, Howe N, Robinson K (1987) A portable system for measuring cutaneous thresholds for warming and cooling. J Neurol Neurosurg Psychiatry 50: 1211-1215

6. Guy RJC, Clark CA, Malcolm PN, Watkin PJ (1985) Evaluation of thermal and vibration sensation in diabetic neuropathy. Diabetologia 28: 131-137
7. Boulton AJM, Hardisty CA, Betts RP, Franks CI, Worth RC, Ward JD, Duckworth T (1983) Dynamic foot pressure and other studies as diagnostic and management aids in diabetic neuropathy. Diabetes Care 6:26-33

8. Dyck PJ, Karnes J, O'Brien PC, Zimmerman IR (1984) Detection thresholds of cutaneous sensation in humans. (In) Dyck PJ, Thomas PK, Lambert EH, Bunge R (eds) Peripheral neuropathy. WB Saunders, Philadelphia, pp 1103-1138

9. Williams G, Gill IS, Aber V, Mather HM (1988) Variability in vibration threshold among sites: a potential source of error in biothesiometry. Br Med J 296: 233-235

10. Dyck PJ (1988) Detection, characterisation, and staging of polyneuropathy: assessed in diabetics. Muscle and Nerve 11: 21-32

11. Consensus statement (1988) Report and recommendations of the San Antonio conference on diabetic neuropathy. Diabetes 37: 1000-1004

12. Boulton AJM, Knight G, Drury J, Ward JD (1985) The prevalence of symptomatic, diabetic neuropathy in an insulin-treated population. Diabetes Care 8: 125-128

13. Katims JJ, Naviasky EH, Rendell MS, Ng LKY, Blecker ML (1987) Constant current since wave transcutaneous nerve stimulation for the evaluation of peripheral neuropathy. Arch Phys Med Rehabil 68: 210-213

14. Boulton AJM, Ward JD (1986) Diabetic neuropathies and pain. Clin Endocrinol Metab 15 (4): 917-931

15. Ganong WF (1981) Review of medical phyisology, 10th edn. Lange, Los Altos, pp 29-42

16. Brazier MAB (1968) The electrical activity of the nervous system, 3rd edn. Pitman Medical, London, pp 79-91

17. Torebjork HE, Hallin RG (1974) Responses in human A and C fibres to repeated electrical intradermal stimulation. J Neurol Neurosurg Psychiatry 37: 653-664

18. Talbot WH, Darian Smith I, Kornhuber HH, Mountcastle VB (1968) The sense of flutter-vibration: comparison of the human capacity with response patterns of mechanoreceptive afferents from the monkey hand. J Neurophysiol 31: 301-334

19. Vallbo AB, Hagbarth K-E, Torebjork HE, Wallin BG (1979) Somatosensory, Proprioceptive and sympathetic activity in human peripheral nerves. Physiol Rev 59 (4): 919-957

Received: 6 March 1989

and in revised form: 5 June 1989

Dr. A.J.M. Boulton

Department of Medicine

Manchester Royal Infirmary

Oxford Road

Manchester M13 9WL

UK 